\title{
La doctrina militar: del pensamiento estratégico a las operaciones militares
}

\section{Military Doctrine: from Strategic Thinking to Military Operations}

\section{Enrique Silvela Díaz-Criado ${ }^{1}$ \\ General de brigada de Artillería, jefe del Mando de Artillería Antiaérea (España)}

Recibido: 02-05-20

Aprobado: 27-06-20

\section{Resumen}

Para pasar del pensamiento y la filosofía de la guerra a su práctica es necesario un puente conceptual que facilite la transformación de los principios en acciones. Ese puente es la doctrina militar, como guía de actuación del mando en combate.

Para entender la doctrina es necesario conocer cómo se genera, de dónde se parte, a través de un análisis histórico y conceptual. Este análisis nos lleva desde las características de las sociedades hasta su esfuerzo en la guerra, acorde con su tiempo.

Una vez efectuado el análisis histórico podemos volcarnos en comprender la doctrina militar actual en el caso que nos preocupa, que es el de España y sus Fuerzas Armadas, que responde igualmente a la sociedad española actual.

Palabras-clave: Doctrina militar, guerra, operaciones, historia, filosofía, sociedad.

\footnotetext{
${ }^{1}$ (esilvela@yahoo.es) Enrique Silvela Díaz-Criado es general de brigada de Artillería. Actualmente es el jefe del Mando de Artillería Antiaérea. Diplomado de Estado Mayor por los Ejércitos de España y Estados Unidos, doctor en Paz y Seguridad Internacional por el Instituto Universitario Gutiérrez Mellado y máster en Ciencia y Arte Militar por el Command and General Staff College de Estados Unidos. Es autor de diversas monografías y artículos profesionales, así como ponente y conferenciante en diversas instituciones.
} 


\begin{abstract}
Moving from the idea and philosophy of war to its practice requires a conceptual bridge, facilitating the transformation of principles into actions. Military doctrine constitutes this bridge, guiding command action in combat.

To properly understand doctrine, we need to know its generation process, where it comes from, through a historical and conceptual analysis. This analysis will lead us from the features of a society to its war effort, concordant with its own time.

Once the historical analysis has been presented, we can dive into current military doctrine, specially in our immediate concern, Spain, and its Armed Forces, which respond to the current state of the Spanish society.
\end{abstract}

Key-words: Military Doctrine, War, Operations, History, Philosophy, Society.

\title{
Práctica, arte y ciencia de la guerra
}

El fenómeno de la guerra es tan antiguo como la humanidad. Su práctica ocasiona muerte y destrucción, por lo que es natural que desde antiguo se haya estudiado y analizado cómo ejecutarla de la manera más eficaz antes de ir al combate. Sin embargo, el estudio reposado no es siempre compatible con la ejecución violenta; tampoco es frecuente que la persona con la energía física, la voluntad y la acometividad necesarias para ser un buen guerrero disponga, al mismo tiempo, de la capacidad intelectual y de comunicación para reflexionar sobre la guerra que practica, así como para volcarlo por escrito.

Aun así, a lo largo de la historia han existido suficientes guerreros con capacidad de reflexión y comunicación, así como suficientes intelectuales con capacidad de observación y comprensión de un fenómeno que no ejercían, como para que se haya ido escribiendo la mejor manera de hacer la guerra en cada momento histórico.

La guerra es un fenómeno social de gran complejidad, quizá el más complejo de todos, sobre todo por sus consecuencias que trascienden el buen gobierno. Ese esfuerzo de reflejar por escrito la mejor forma de hacer la guerra, por tanto, es igualmente complejo, tanto en extensión como en profundidad. Los escritos sobre la guerra tienen que abarcar desde la ejecución de acciones manuales individuales de manejo de un arma hasta el más profundo análisis sobre su sentido. Y el manejo del arma es tan cuestión de vida o muerte para quien la sostiene en su mano, como lo es también el sentido de la guerra para quien la decide y dirige.

Por eso, desde la Antigüedad existen escritos sobre la guerra para su comprensión y su mejor práctica. Estos escritos son acordes con el estilo cultural 
y social de su tiempo. Por ello, en la actualidad que nos atañe, es necesario comprender dos ideas fundamentales para entender la guerra del siglo XXI: las sociedades hacen la guerra de acuerdo con su estructura social; los que escriben sobre la guerra lo hacen igualmente de acuerdo con su aproximación cultural ${ }^{2}$.

La necesidad de explicar la guerra a las siguientes generaciones ha llevado desde el inicio a buscar un relato "científico" o al menos racional de su ejecución ${ }^{3}$. Sin embargo, la citada complejidad, la variedad de situaciones y las personalidades en juego hacían difícil encontrar un método aplicable de forma generalizada.

Al ser la guerra un asunto de vida y muerte también ha tenido siempre en su pensamiento una orientación transcendental. Antes de lanzarse a la batalla era necesario preparar el alma para el resultado, tanto individual como la responsabilidad asumida por el jefe de las vidas que pudieran pesar en su conciencia. Por eso la reflexión sobre la guerra ha incluido la preocupación por sus causas, por si era suficientemente justificada, atendiendo a una filosofía metafísica de la violencia ${ }^{4}$.

Ante este enfoque se han producido dos respuestas históricas. Por un lado, los que despreciaban cualquier estudio de la guerra; bastaba con su práctica; con el ejercicio, la preparación, la destreza individual y la experiencia era suficiente. También se despreciaban sus consecuencias, la guerra era una práctica natural de la humanidad en la que triunfaba el más fuerte. Bastaba con ser más fuerte, por tanto.

Por otro, quienes han tratado de reducir la guerra a una ciencia o un procedimiento que podía ser aprendido y aplicado tal cual, con sus reglas, principios y resultados. En este apartado se incluyen desde el diestro manejo de las armas, pasando por la organización básica de las fuerzas, hasta directrices para su empleo táctico ordenado: un enfoque científico.

Como solución intermedia, se ha atribuido a la conducción de la guerra la categoría de arte. Al ser un arte, no se desprecia la ciencia, pero se reconoce que no se puede reducir su práctica al mero estudio de principios y procedimientos, que es imprescindible contar con talento e inspiración, como el de un artista que no está reñido con el aprendizaje, el estudio y la experiencia. El puente entre arte y ciencia se ha apoyado siempre en una filosofía de la guerra, poniendo el estudio de sus principios fundamentales en parangón con los estudios filosóficos de cada época.

\footnotetext{
${ }^{2}$ González-Pola de la Granja emplea el término "mentalidad militar". Pablo González-Pola de la Granja. La configuración de la mentalidad militar contemporánea y el movimiento intelectual castrense. El siglo crítico 1800-1900. Universidad Complutense, Madrid, 2002.

${ }^{3}$ Como por ejemplo, la obra del griego Tucídides, que proporciona una explicación racional a las Guerras del Peloponeso, escrita en el siglo IV a.C. Tucídides. Historia de la Guerra del Peloponeso. Planeta De Agostini, Barcelona, 1996.

${ }^{4}$ Alex J. Bellamy, Guerras justas de Cicerón a Iraq. Fondo de Cultura Económica, Madrid, 2009.
} 
Los distintos periodos históricos han volcado este equilibrio entre práctica, arte y ciencia en un sentido o en otro, acorde con su propia sociedad y cultura. En la Antigüedad clásica, el equilibrio era bastante ajustado, pasando en la Edad Media a desplazarse hacia la práctica; el Renacimiento trajo un retorno de la ciencia y el arte, buscando una "teoría" de la guerra. La evolución del pensamiento humano hacia la aplicación generalizada del método científico ha ido poco a poco desequilibrando este dilema entre práctica, arte y ciencia en favor de esta última. La filosofía de la modernidad, con especial empeño en apoyarse en la ciencia, ha sido la protagonista de los escritos más recientes sobre la guerra. Pero la posmodernidad, con su exclusión de todo lo que no sea ciencia, la ha empujado radicalmente en dicha dirección, abandonando cualquier metafísica y retorciendo su verbalización en manos del giro lingüístico.

Los ejércitos que saben que algún día participarán en combate han tratado de sobreponerse al debate reflexionando en todos los órdenes, el de la práctica, el del arte y el de la ciencia. A lo largo del siglo XX, continuado en el XXI, la denominación que ha recibido esta reflexión ha sido la de "doctrina", que va a ser la protagonista de este escrito. La doctrina ha sido la forma de expresión militar profesional de la reflexión sobre sí mismo para su actuación en combate, dejando aparte la metafísica y la filosofía. Dejadas aparte no significa que hayan sido ignoradas: bien al contrario, son la fuente de pensamiento de los que escriben doctrina, pero no la reflejan de forma explícita.

La doctrina es la parte más específicamente militar de los escritos sobre la guerra. Por supuesto que tiene que contemplar sus causas y su filosofía. Por supuesto que tiene que contemplar la percepción social de sus fuerzas armadas. Pero de todo lo que se escribe sobre la violencia, sobre la guerra, sobre las fuerzas armadas, la doctrina es la que va orientada a su empleo en combate, que es la expresión principal de su acción. La doctrina es la gramática de la guerra ${ }^{5}$.

\section{Doctrina militar}

La doctrina es, ante todo, una teoría de la victoria ${ }^{6}$. Cuando es la vida lo que se arriesga -no el resultado de una operación económica o de un partido deportivo-, solo vale ganar. No hay sustituto para la victoria. Aunque sí haya restricciones, tampoco hay reglas, ni justicia. No tiene por qué ganar el mejor, ni el más bueno. No hay merecimiento de la victoria, la victoria no tiene apellidos. No se busca un combate equilibrado, no se otorgan ventajas ni compensaciones a un enemigo, como sí se puede hacer con un adversario.

\footnotetext{
${ }^{5}$ Pedro Valdés Guía, La dirección de la guerra: conducción operacional y gobierno político de las operaciones militares. Tesis Doctoral, Universidad de Navarra, Pamplona, 2019.

${ }^{6}$ Stephen Peter Rosen. Winning the Next War: Innovation and the Modern Military. Cornell University Press, Ithaca, 1994.
} 
El que no haya reglas ni justicia no quiere decir que el combatiente no se ponga límites, puesto que sí hay respeto a los derechos humanos, respeto al derecho internacional. Pero es un respeto autoimpuesto por las sociedades democráticas modernas, por las sociedades antiguas que tenían un respeto a la dignidad humana. A lo largo de la historia han existido sociedades que no han tenido ese respeto, nadie dice que no puedan volver.

Aunque no tiene apellidos, la victoria tiene muchas expresiones en la realidad, sobre todo a posteriori. Ganar puede ser simplemente no perder contra un enemigo superior, puede ser frenar al invasor, puede ser sobrevivir. Pero eso es la práctica, no la teoría. En la teoría solo está la victoria, no se teoriza con cómo empatar. No se guerrea para perder, aunque se asuma que la derrota es posible, incluso probable.

Por ello, la doctrina es una teoría de la victoria. Un desarrollo escrito de cómo se puede y se debe conseguir. Qué factores son necesarios, qué principios gobiernan la guerra, qué acciones hay que emprender, qué actitudes y procedimientos llevan a la victoria. La victoria que hay que conseguir en cada combate, cada batalla, cada operación, victoria final en la guerra.

La doctrina la escriben los propios militares. Se fundamenta en la sociedad a la que se pertenece, con su cultura, sus valores, su legislación y su estilo que son los que han recibido los militares en su educación antes de ingresar en los ejércitos. De forma inconsciente refleja esa filosofía y el pensamiento predominante en su época ${ }^{7}$.

La doctrina se escribe sobre las operaciones militares. Debe contener, por supuesto, las referencias esenciales de la institución, pero su objetivo son las operaciones. Por tanto, no es un manual ni un ensayo de filosofía de la guerra o de estrategia; tampoco debe descender a los procedimientos técnicos de manejo de armamento o de funcionamiento de algunos elementos militares. La doctrina proporciona coherencia a las operaciones militares, en un contexto estratégico y contando con los medios existentes en el momento de su redacción.

Estos límites, superior el de la estrategia e inferior el de la técnica, no están determinados, son permeables y van a depender del espíritu que ilumine a los redactores y decisores. No tienen por qué ser similares en distintos países o momentos históricos. Aun más, existe una indeterminación sobre el campo de la doctrina considerada como tal y los escritos que son "doctrinales", pero no son doctrina. Estos últimos pertenecen al dominio de la táctica, en donde se determinan procedimientos de empleo local de fuerzas específicas, con cometidos propios. Los textos que reciben directamente el nombre de doctrina suelen referirse al llamado nivel o "arte" operacional, que es el "nexo de unión

\footnotetext{
${ }^{7}$ Conrado Cebollero Martínez, Escribir para pensar: la doctrina como motor de la innovación. Instituto Español de Estudios Estratégicos, 2019. Disponible en: http://www.ieee.es/contenido/ noticias/2019/03/DIEEEO21_2019CONCEB-doctrina.html
} 
entre el Nivel Estratégico y el Táctico, donde se materializa verdaderamente la acción conjunta como integradora de las formas específicas de actuación de cada ejército". En cualquier caso, los equipos que dirigen la edición de unos como otros quedan bajo la denominación de doctrina.

El contenido de la doctrina sobre las operaciones militares debe buscar un equilibrio difícil de alcanzar, del que existen buenos ejemplos históricos. Por una parte, está la tendencia a detallar los procedimientos que se deben aplicar en cada caso, dejando un estrecho margen de decisión a los ejecutores que deben ajustarse a lo redactado; en el otro extremo está la mera recopilación de máximas y principios a tener en cuenta, dejando gran capacidad de decisión e inventiva al ejecutor de la doctrina.

El punto de equilibrio dependerá del contexto histórico y cultural, así como del impulso personal de quien lo acometa. Al final, una doctrina debe contener parte de ambas tendencias, configuradas en todo o en parte de los siguientes contenidos:

- Contexto político y legal en el que se van a desarrollar las operaciones.

- Interpretación del entorno operativo contemporáneo en el que van a tener lugar.

- Articulación de la cadena de mando y decisión desde la política hasta la ejecución de las operaciones, incluyendo la articulación de la Fuerza que las ejecuta.

- Articulación de los niveles de conducción de las operaciones.

- Organización del espacio donde tendrán lugar las operaciones.

- Principios generales de conducción y ejecución de las operaciones.

- Atribuciones, responsabilidades y cometidos del mando militar.

- Funciones principales que se desarrollarán y responsabilidades específicas por elementos.

- Relaciones que se establecen entre los elementos que participan en las operaciones.

- Conceptos necesarios para utilizar una cultura e interpretación común.

- Definiciones terminológicas necesarias para emplear un lenguaje común.

\footnotetext{
${ }^{8}$ Alberto Asarta Cuevas, El nivel operacional. Monografías n ${ }^{\circ}$ 149, CCDC, IEEE, Madrid 2016 , p. 10 .
}

Araucaria. Revista Iberoamericana de Filosofia, Política, Humanidades y Relaciones Internacionales, año $22, \mathrm{n}^{\circ} 44$. Segundo semestre de 2020. Pp. 545-562. ISSN 1575-6823 e-ISSN 2340-2199 https://dx.doi.org/10.12795/araucaria.2020.i44.25 
Como simplificación de lo anterior, la doctrina va a contener principalmente una articulación de las operaciones, más los principios, conceptos y definiciones necesarios para obtener una interpretación común.

La doctrina no se refiere a un conflicto ni a un enemigo concreto, sino que se trata de un estudio abstracto de la mejor forma de organizarse y ejecutar la batalla. Debe permitir a cualquier comandante militar la concepción de cualquier operación militar y, junto con su Estado Mayor, la elaboración de un plan, la organización de sus medios y la conducción de la batalla.

Para ello, la doctrina, como el origen etimológico de la palabra muestra, se convierte en un instrumento didáctico que sirve para enseñar a las generaciones de militares, previamente a su participación en combate, cómo prepararse y cómo actuar con una gramática común.

El origen de la doctrina está, sobre todo, en la experiencia, en el buen aprovechamiento de la experiencia ajena. Por eso bebe de la historia, ya que es la que nos proporciona las lecciones de la experiencia sin sus costes. No hay más duro aprendizaje que en cabeza propia. Pero además hay que considerar otros factores, como las necesidades de los Estados, el impacto de la tecnología y las características sociológicas de los ejércitos y las sociedades 9 .

\section{Evolución histórica de la doctrina actual}

Las sociedades en conflicto potencial han buscado siempre disponer de una ventaja frente a un adversario; pero el número de posibles ventajas es amplio. Hay ventajas basadas en el número, la masa: ya sea masa de personas por superioridad demográfica o masa de recursos económicos o materiales. También se puede alcanzar la superioridad por el conocimiento, ya sea tecnológico o de una mejor organización, cohesión o forma de combatir. Igualmente se puede alcanzar mediante la mera voluntad, la capacidad de asumir riesgos y jugarse la vida de no tener nada que perder. Existirían muchas otras expresiones de ventaja que tradicionalmente se pueden agrupar en tres campos: querer, saber y poder; es decir, la voluntad, el conocimiento y los recursos. Estos tres se pueden combinar de diversas formas; lo que las doctrinas militares han hecho ha sido seleccionar alguna de estas combinaciones en un modo específico de hacer la guerra a lo largo de la historia, en función del querer, saber y poder de cada momento.

Como antes se ha indicado, los ejércitos han combatido como han vivido, de acuerdo con su sociedad. En una gran simplificación, Alvin

\footnotetext{
9 Carlos Javier Frías Sánchez, El sistema internacional y las Fuerzas Armadas en el horizonte 2050. Documento de Opinión 106. IEEE, Madrid, 2017.
} 
Toffler ${ }^{10}$ ha identificado tres grandes periodos, tres "olas" en los modos de combatir: una primera ola de guerra basada en el músculo, cara a cara, que se remonta al neolítico; una segunda ola, a partir de la revolución industrial, en que el desarrollo demográfico y económico ha permitido ejércitos mucho más numerosos, dotados de máquinas, que hacen la guerra a cada vez más distancia; pronostica una tercera ola, en la que estaríamos ahora inmersos, donde predomina la información y se produce una desmasificación y una personalización del enfrentamiento.

A lo largo de la primera ola, se pueden identificar igualmente numerosos modos de combatir muy distintos. La historia nos relata frecuentes enfrentamientos de pueblos nómadas contra pueblos sedentarios: los nómadas combaten desde su menor número, pero con mayor cohesión y con experiencia de su vida pastoril de conductores de ganado; los sedentarios, habitualmente más numerosos y dotados de mayor organización, podían carecer de voluntad o experiencia útil para el combate ${ }^{11}$.

En la antigua Grecia nace una forma peculiar de combate que, con el tiempo y la evolución, se ha venido a denominar "el modo occidental de hacer la guerra"12. Los pueblos griegos estaban divididos en ciudades - polis-que se enfrentaban unas a otras. Estas poléis estaban formadas por ciudadanos libres, pequeños propietarios agrícolas que participaban en los combates aportando su armamento. En su participación en combate destacaba la igualdad social entre ciudadanos. Los pequeños ejércitos griegos formaban en cuadros denominados "falanges" con poca distancia entre sus componentes codo con codo. Estas falanges chocaban unas con otras, frente a frente, hasta que una cedía y dejaba el campo a la triunfante. Contrasta esta forma de combatir con los antiguos persas - conocidos como medos por los griegos-, a los que se enfrentaron en las llamadas guerras médicas. Los persas eran un pueblo sedentario con una mayoría de la población sometida a una pequeña casta dominante. Sus ejércitos estaban formados por siervos en masa con poca motivación pero muchos recursos, mandados por buenos generales. Los ejércitos griegos, mucho menos numerosos, formados por ciudadanos libres y con gran motivación, acabaron alcanzando la victoria.

La expansión de Alejandro y luego de Roma daría primacía a esta forma occidental de guerra, cada vez más compleja, pero basada inicialmente en el ciudadano combatiente, aprovechando al máximo sus recursos con una fuerte cohesión dentro de la unidad militar. El feudalismo cambió la forma de combatir al igual que cambió la sociedad. La fragmentación social llevó a una especialización en la que las élites dominantes, habitualmente de origen

\footnotetext{
${ }^{10}$ Alvin Toffler, La tercera ola. Barcelona: Plaza \& Janes, 1998.

${ }^{11}$ Azar Gat, War in Human Civilization. Oxford: Oxford University Press, 2008.

${ }^{12}$ Geoffrey Parker, The Cambridge History of Warfare. Cambridge: Cambridge University Press, 2005 .
} 
externo, asumían tanto el mando político como la ejecución militar, mientras que los campesinos pasan a condiciones de servidumbre, protegidos por sus dueños feudales y sin participar de la contienda. Por ello, se abandonan los cuadros de infantería y el elemento principal de combate pasa a ser la lanza a caballo, el caballero con costosa armadura.

La baja Edad Media y el Renacimiento trajeron un desarrollo demográfico, económico y tecnológico que influyó en los modos de la guerra, sobre todo a partir de la aparición y domesticación de la pólvora. La artillería era un arma muy cara, por lo que ya no era posible para los nobles obtener una superioridad local en su feudo. Los reyes, aliados con el capital formado en las ciudades, fueron los nuevos protagonistas del poder militar ${ }^{13}$. La nueva igualdad en la población recuperó la forma de las falanges con los tercios españoles, formados por ciudadanos voluntarios y remunerados. El protagonismo de las ciudades también se refleja en los asedios, así como en la tecnología defensiva abaluartada.

Hasta entonces, los escritos sobre la guerra eran históricos y tácticos. Se explicaba la mejor organización de la fuerza y se relataban batallas, se redactaban tratados del arte o la teoría militar, pero todavía no se escribía sobre lo que hoy podemos entender como doctrina. Durante muchos años, se mantuvo la sabiduría del Imperio romano, reflejada en el tratado de asuntos militares de Vegecio, pero en esos tiempos comienzan a trasladarse por escrito algunas normas de la guerra, como las elaboradas por Sancho de Londoño a instancias del Duque de Alba en $1568^{14}$.

La denominación de "doctrina" para este campo del saber entre el arte y la ciencia militar se remonta al siglo XIX, por analogía con la doctrina religiosa como conjunto de reglas de actuación. Escritos sobre la guerra existen desde todas las épocas, pero se puede poner el inicio de los escritos científicos que explican la mejor forma de ejecutarla en la Ilustración. Los generales de la época, como Mauricio de Sajonia, relataban de forma ilustrada su propia práctica en combate. Este modelo alcanza su culmen en los intérpretes de Napoleón, como Clausewitz y Jomini. Clausewitz ${ }^{15}$ escribe filosofía de la guerra, que nos sirve para entenderla, aunque también proporciona principios y conceptos útiles para su ejecución, en lo que él llama "teoría". Jomini sí que se vuelca con perspectiva científica en un estudio principalmente doctrinal que fue estudiado durante años en las escuelas de formación militar europeas y norteamericanas.

\footnotetext{
${ }^{13}$ Charles Tilly, Capital, coerción y Estados europeos: 900 - 1990. Madrid, Alianza Editorial, 1992.

14 Sancho de Londoño, Discurso sobre la forma de reducir la Disciplina Militar a mejor y antiguo estado. Ministerio de Defensa, Madrid, 1992.

15 Jon Tetsuro Sumida, Decoding Clausewitz: A New Approach to On War. Lawrence, Kansas: University Press of Kansas, 2008.
}

Araucaria. Revista Iberoamericana de Filosofí, Política, Humanidades y Relaciones Internacionales, año $22, \mathrm{n}^{\circ} 44$. Segundo semestre de 2020. Pp. 545-562. ISSN 1575-6823 e-ISSN 2340-2199 https://dx.doi.org/10.12795/araucaria.2020.i44.25 
Por tanto, el origen de los escritos doctrinales es, principalmente, histórico. Se analizan las campañas de genios militares como Napoleón para extraer lecciones de sus éxitos, para ser capaz de reproducirlos en el futuro. Sin embargo, los lectores de Jomini no fueron todo lo victoriosos que esperaban, mientras que, con el tiempo, se vio que algunos comandantes que sí obtenían victorias, como Moltke en la guerra franco-prusiana, citaban a Clausewitz como referencia.

Jomini y Clausewitz, que son contemporáneos, nos enseñan que no todos los que escriben lo hacen siguiendo la misma línea de pensamiento de su época. Jomini es un ilustrado que pretende convertir en ciencia geométrica la actividad humana, mientras que Clausewitz es un idealista anti-ilustrado que filosofa sobre la guerra, introduciendo una perspectiva teleológica kantiana. Esta perspectiva teleológica es la que otorga superioridad a la interpretación clausewitziana sobre la jominiana, ya que se adapta a la realidad de la época - de cada época-. En el caso concreto de Napoleón, el gran cambio que produce la revolución francesa es la superioridad del pueblo en armas sobre los pequeños y valiosos ejércitos casi profesionales de los reyes ilustrados.

El siguiente proceso que irá cambiando la doctrina militar será la extensión de la revolución industrial, que incrementa tanto la potencia demográfica como de armamento disponibles en una contienda. Precisamente Moltke, estudioso de Clausewitz, es quien aprende a aprovechar tanto el nacionalismo panalemán como el desarrollo tecnológico e industrial que suponen las nuevas armas de fuego -como el fusil de percutor de aguja-, el telégrafo y el ferrocarril.

La combinación de desarrollo tecnológico, económico y demográfico, junto al nacionalismo y la filosofía supremacista que se abre paso, culminan en la primera guerra mundial. Millones de personas manejando millones de toneladas de armamento y equipo se enfrentaron con un notable desprecio por la vida siguiendo una doctrina de ofensiva a ultranza -de origen francés-. Desprecio que no solo partía de los comandantes militares, sino en su origen de las sociedades que enviaban voluntariamente a sus hijos con orgullo racial.

En los primeros años del siglo XX es cuando se comienzan a codificar con formatos modernos los escritos doctrinales, algo imprescindible para comunicar ese pensamiento común a organizaciones tan grandes y complejas como las que nacen en esos años. La doctrina adquiere una redacción articulada y moderna, más sistematizada, basada en principios que se van estudiando en cada país.

Si bien el desarrollo de la guerra de sucesión norteamericana pasó casi desapercibido para los teóricos militares europeos, no pudieron sustraerse al gran empate táctico producido en la primera guerra mundial, contra las previsiones doctrinales. Ambas contiendas llevaron a un debate que hoy continúa entre 
dos formas de afrontar las operaciones militares: con predominio del fuego o predominio de la maniobra ${ }^{16}$.

Este debate se puede ampliar aun más, a un debate entre quienes optan por un modo de combatir que parte de la habilidad de los comandantes y los oficiales para concebir y ejecutar las operaciones asumiendo riesgos, frente a otro modo que busca apoyarse sobre la superioridad material donde exista, a base de predominio demográfico e industrial. Estos dos modelos estarían respectivamente representados por Alemania y Estados Unidos en la Segunda Guerra Mundial.

En esta época cristaliza igualmente, partiendo de teóricos soviéticos, conscientes de los grandes espacios en los que podría combatir su patria, el concepto de un nivel intermedio de la conducción de la guerra entre el estratégico y el táctico. Este nivel, de las operaciones militares y, por ello, llamado operacional, pasa a protagonizar los escritos doctrinales por entonces.

A partir de la aparición del arma nuclear, epítome del poder industrial, la doctrina militar cede inicialmente paso a la estrategia nuclear dominante. La masa, la superioridad brutal que concede el arma nuclear hace palidecer la adquisición de ventajas con otros medios. Sin embargo, la conciencia de que el empleo del arma nuclear conduce a la destrucción mutua, la desigualdad convencional entre bloques y la necesidad de emplear fuerzas en escenarios secundarios revitaliza los estudios de doctrina.

El desarrollo científico y la mentalidad industrial contemporánea alejan a la doctrina y a quienes la promueven o escriben del pensamiento filosófico para acercarlo al económico y empresarial. La dirección científica de las empresas iniciada por Taylor y Fayol, los estudios de investigación operativa y estadística y el progreso de la sociología llevan a codificar de forma más detallada la nueva doctrina para las operaciones. Esta postura recibió un notable impulso por el secretario de Defensa de los Estados Unidos, Robert McNamara, protagonista de esa formación empresarial de contenido científico, que impulsó su aplicación a la doctrina norteamericana, a su vez la de referencia para todos los países desarrollados, especialmente en la OTAN ${ }^{17}$.

De ahí nacen unos procedimientos que procuran operacionalizar todas las variables posibles, unificando los métodos de planeamiento sobre líneas de acción alternativas y empleando o dotando de nueva vida a conceptos como el de "centro de gravedad". Procedimientos que, de nuevo, retratan una cultura occidental en expansión económica. La teoría crítica influye igualmente en la

\footnotetext{
${ }^{16}$ Para conocer la evolución doctrinal entre la Primera y Segunda Guerras Mundiales, las doctrinas de fuegos y de maniobra y las de ofensiva y defensiva conviene leer el blog del coronel Carlos Javier Frías en GESI. Disponible en: https://global-strategy.org/author/carlos/ Consultado el 16 de marzo de 2020 .

${ }^{17}$ Lawrence S. Kaplan, Ronald D. Landa y Edward J. Drea, “The McNamara Ascendancy; 19611965". History of the Office of the Secretary of Defense, Vol. V. OSD, Washington D.C. 2006.
} 
previa inclusión en todas las doctrinas de referencias sociales y de derecho internacional de los conflictos armados que minimicen los daños ocasionados.

En esta época renace el debate entre ciencia y arte en el sentido procedimental y protocolario de la acción colectiva frente a la libertad y creatividad del individuo. Es conocido el debate entre dos escuelas de pensamiento norteamericano, la nacida de la Segunda Guerra Mundial que desconfía de la iniciativa del subordinado, exigiendo procedimientos detallados comunes y la que confía en su creatividad. Este debate, en Estados Unidos, fue inicialmente ganado por los procedimentales ${ }^{18}$. El debate no ha cesado en el paso del siglo XX al XXI. La necesidad de conseguir una mayor eficiencia, en consonancia con la evolución de los conceptos de dirección estratégica de la empresa, ha ido arrinconando las doctrinas excesivamente procedimentales, recuperando la iniciativa del subordinado orientada por la misión asignada, en lo que se ha venido a denominar "mando orientado a la misión"19.

El giro lingüístico ha tenido un protagonismo menor, pero significativo en la redacción de las doctrinas. Se ha buscado un lenguaje que asume la sustitución de la realidad sobre la base de un notable aumento del número de conceptos y definiciones abstractas que retratan la realidad del campo de batalla, pero en niveles contenidos. Hay una excepción en que la filosofía de Deleuze y Derrida ha tomado un gran protagonismo, partiendo de una iniciativa israelí llamada "diseño operacional sistémico" que fue parcialmente imitada en Estados Unidos y algunos países de la OTAN. En el caso israelí, se atribuye la derrota ante Hizbolá, en el conflicto de 2006 en la frontera sur libanesa, a la equivocada aplicación de esta doctrina ${ }^{20}$. En la OTAN tomó la forma, menos acusada, de una nueva orientación a las "operaciones basadas en efectos" ${ }^{21}$ que no ha desaparecido, pero sí ha suavizado su radicalidad.

\section{Las doctrinas actuales}

La elaboración y redacción de documentos doctrinales es, a fecha de hoy, un proceso constante en los países aliados occidentales como España. Las doctrinas se revisan periódicamente para adaptarse al entorno cambiante. Incorporan

\footnotetext{
${ }^{18}$ Paul H. Herbert, Deciding What Has to Be Done: General William E. DePuy and the 1976 Edition of FM 100-5, Operations. Leavenworth Papers $N^{\circ} 16$, Combat Studies Institute, US Army CGSC, Fort Leavenworth, Kansas, 1988. pp. 51-59. Disponible en: http://www.cgsc.edu/carl/ resources/csi/herbert/herbert.asp

${ }^{19}$ Denominado mission command en inglés.

${ }^{20}$ Matt M. Matthews, We Were Caught Unprepared: The 2006 Hezbollah-Israeli War. The Long War Series Occasional Paper 26. Fort Leavenworth, Kansas: Combat Studies Institute Press, 2008.

${ }^{21}$ Phillip S. Meilinger, The origins of effect-based operations. Joint Force Quarterly, otoño 2004, $\mathrm{N}^{0}$ 35, pp. 116-122. Disponible en: http://www.docstoc.com/docs/890059/The-Origins-of-EffectsBased-Operations
}

Araucaria. Revista Iberoamericana de Filosofia, Politica, Humanidades y Relaciones Internacionales, año $22, \mathrm{n}^{\circ} 44$. Segundo semestre de 2020. Pp. 545-562. ISSN 1575-6823 e-ISSN 2340-2199 https://dx.doi.org/10.12795/araucaria.2020.i44.25 
progresivamente los modos y principios de la sociedad contemporánea, puesto que son los modos y principios de sus redactores. Una vez promulgadas, son la referencia de consulta principal en cualquier argumento profesional.

España ha actualizado recientemente su principal documento doctrinal, la publicación doctrinal conjunta PDC-01(A) Doctrina para el empleo de las Fuerzas Armadas, promulgada el 27 de febrero de 2018. Este documento ilustra el proceso doctrinal y la adaptación a la sociedad antes mostrado, con las particularidades propias de la profesión militar de sus redactores. De manera similar se generan las doctrinas de la OTAN como alianza, al igual que las de los países principales que la componen. Son menos conocidas y divulgadas las doctrinas de países no OTAN, que no son objeto de este escrito. Los iberoamericanos toman como referencia los procesos de la Alianza, pero los países no occidentales tienen una diferente idiosincrasia.

En el caso español, la PDC-01(A) refleja en su contenido las características de la sociedad española actual. Su proceso de redacción parte de un análisis estratégico del entorno global de seguridad, basado en documentos producidos igualmente en el seno de las Fuerzas Armadas y, por supuesto, en la Estrategia de Seguridad Nacional del Gobierno español como referencia fundamental. La doctrina hace mención expresa de los bienes y valores que se consideran como intereses nacionales, derivados de la herencia histórica y cultural. De entre ellos, considera vital la preservación de la "soberanía, la independencia, la integridad territorial y el ordenamiento constitucional como elementos constitutivos del Estado, así como la libertad, la vida y la prosperidad de los españoles, dentro y fuera del territorio nacional"'22.

A continuación, menciona otros intereses que considera estratégicos, como el suministro energético y de recursos básicos, el comercio internacional, las infraestructuras críticas y la pertenencia a alianzas. De la misma forma refiere otros intereses nacionales "derivados de la posición que ocupa España en la comunidad internacional, de su contribución a la causa de la paz y la libertad, y de su relación con las naciones de la misma comunidad histórica y cultural"23, reconociendo que "los valores que defiende España, propios de la civilización occidental, son comunes a la Unión Europea y a la Alianza Atlántica"24.

El empleo de las Fuerzas Armadas se describe encuadrado en un marco legal, ajustado a los principios de legalidad y legitimidad, partiendo de la Constitución española y reconociendo expresamente la Carta de Naciones Unidas, el Tratado de Washington para la Alianza Atlántica y el Tratado de la Unión Europea. En este marco, la legislación aplicable establece un sistema de seguridad nacional que parte del presidente del Gobierno y cuenta con diversos

${ }^{22}$ Ministerio de Defensa. Publicación Doctrinal Conjunta PDC-01(A) Doctrina para el empleo de las FAS. Madrid 2018, p. 23.

${ }^{23}$ Ibid. p. 24.

${ }^{24}$ Ibid. p. 24.

Araucaria. Revista Iberoamericana de Filosofia, Politica, Humanidades y Relaciones Internacionales, año $22, \mathrm{n}^{\circ} 44$. Segundo semestre de 2020. Pp. 545-562. ISSN 1575-6823 e-ISSN 2340-2199 https://dx.doi.org/10.12795/araucaria.2020.i44.25 
elementos a todos los niveles de la administración. La doctrina proporciona cohesión para el entendimiento armonizado de todos estos elementos y procedimientos hasta el empleo de las Fuerzas Armadas en cualquier situación.

Las propias Fuerzas Armadas merecen una atención detallada a su estructura, su concepto de empleo, su financiación y sus misiones, conforme a la legislación vigente. Acorde con el momento actual, las capacidades militares se definen en un entorno de desarrollo tecnológico, donde la innovación y la transformación militar son esenciales. De acuerdo con estas ideas se procede a la articulación de la fuerza en sus capacidades y su organización.

La parte fundamental es la volcada en las operaciones, como corresponde a una doctrina. Para ello, la doctrina, partiendo de los principios de empleo del instrumento militar, estudia el entorno operativo contemporáneo, los potenciales adversarios, el espacio de las operaciones y el espectro de los conflictos, contribuyendo a articular el escenario en el que se emplean las Fuerzas Armadas. Este escenario es el que necesita una permanente actualización, lo que se comprueba en esta edición de la doctrina, donde ya se contemplan los ámbitos cognitivo y ciberespacial que están tan presentes en nuestra sociedad. Igualmente, en el estudio de los potenciales adversarios, están también incluidos los nuevos conceptos de zona gris, la amenaza híbrida y con especial atención a los actores no estatales, además de los adversarios convencionales.

El desarrollo de las operaciones se efectúa con principios, conceptos y definiciones adaptados a los niveles de las operaciones, estratégico, operacional y táctico. Estos conceptos y definiciones cobran todo su sentido al estar enmarcados en los contenidos previos de marco legal y entorno de seguridad. Todo ello, se vuelca en las consideraciones sobre el mando militar que es la figura que proporciona cohesión y decisión al conjunto, personalizando estas acciones teóricas en decisiones que se tomarán de forma individual.

Para comprender este conjunto de contenidos es esencial conocer el proceso de redacción y promulgación de un documento de esta trascendencia. No es el capricho de un oscuro grupo de redactores expertos; bien al contrario, el proceso es colectivo e involucra a todos los elementos relevantes de las Fuerzas Armadas.

En primer lugar, este es un documento que reemplaza a uno anterior y que tiene ya una vida prevista para que se actualice regularmente. Inicialmente, el jefe de Estado Mayor de la Defensa proporciona directrices para su contenido, partiendo de la versión anterior. Un equipo multidisciplinar y con participación de todos los organismos inicia la redacción del nuevo documento. Los primeros borradores circulan dentro de este equipo hasta que se logra un borrador final. Ese borrador se distribuye para comentarios de todos los organismos con lo que son ojos nuevos los que lo leen y proporcionan comentarios y debaten el 
contenido. Cuando se logra un acuerdo de todos, el borrador se transforma en consolidado y regresa a su origen, el jefe de Estado Mayor de la Defensa, para su promulgación.

Es un trabajo en el que se ha dado voz a todas las Fuerzas Armadas que se ha consultado y circulado por todos sus organismos. En los equipos de trabajo, se han incorporado expertos no solo militares, también civiles en los campos donde ha sido necesario, aunque el contenido es puramente militar.

Tal y como antes se ha definido, la doctrina es una teoría de la victoria. El JEMAD y las Fuerzas Armadas han definido en la PDC-01(A) qué elementos son esenciales para la victoria. Por eso está contemplado el marco legal y los principios y valores que emanan de la sociedad española, ya que la victoria es cosa de todos, toda España debe estar implicada, no se puede escribir una doctrina militar ajena a la sociedad a la que defiende.

Esa doctrina tiene que estar acorde con el tiempo y el escenario en que actuarán las Fuerzas Armadas. Por eso es esencial para la victoria que se enmarque la actuación militar española en el entorno contemporáneo y que tenga en cuenta las evoluciones más recientes, tanto tecnológicas como de valores. Y, por supuesto, dentro de ese marco, es necesario aplicar los principios y conceptos militares que cobran todo su sentido dentro del entorno contemporáneo. Esos serán los procedimientos que nos lleven a la victoria si llega el caso.

Aun así, y precisamente por estar enmarcados en la actualidad española, la doctrina recuerda que las Fuerzas Armadas necesitan una estructura y una financiación que dote de contenido a las capacidades y procedimientos teóricos que se exponen, pues de nada valen los principios si no hay recursos detrás. La doctrina no entra en la realidad de esos recursos, pero es evidente la necesidad de que sea coherente con su disponibilidad. Pues la victoria necesita ventajas, como antes se ha mostrado. Y entre esas ventajas no está solo el saber, al que responde la doctrina, sino también el querer y el poder, que es donde se encuentran los principales retos de la España contemporánea.

\section{Conclusiones}

A lo largo de estas páginas se ha presentado cómo se escribe la doctrina militar. La perspectiva de partida es su utilidad en el momento actual, para lo que es necesario comprender su origen histórico. Se aprecia que la doctrina, como teoría de la victoria, refleja profundamente el modo de ser y de pensar de cada sociedad, no lo puede ser menos en la actual. Modo de ser en la forma de combatir, modo de pensar en la forma de escribir. 
Ese modo de ser, en la España de la primera mitad del siglo XXI, es acorde con la época actual: una sociedad basada en el capitalismo liberal que cree fervientemente en el multilateralismo y en la solución a los conflictos sobre la primacía del derecho internacional. Por eso, la doctrina recurre a una compleja organización militar dotada de recursos tecnológicos -capitalismo- en un marco de empleo jurídico muy definido y en el entorno de una alianza de países de cultura similar.

La forma de escribir es directa, escueta y bien estructurada en torno al marco jurídico y normativo mencionado. Diríase más escrita por juristas que por ingenieros, aunque tiene una mezcla de ambas, con perspectiva sociológica. Refleja el espíritu interdisciplinar de sus redactores militares que buscan la seguridad jurídica de la redacción sin descender al detalle, pero avanzan en conceptos y definiciones organizativas más técnicas que normativas.

Al final, con el modo de ser y el modo de escribir, queda una definición de ventajas en la guerra que llevan a la victoria, basadas en la legitimidad que impulsa la voluntad, en la capacidad tecnológica que acompaña el poder, pero, sobre todo, en la mezcla de arte y ciencia que proporciona el saber militar. 


\section{Referencias bibliográficas:}

Asarta Cuevas, Alberto, El nivel operacional. Monografías nº 149, CCDC, IEEE, Madrid, 2016.

Bellamy, Alex J., Guerras justas de Cicerón a Iraq. Fondo de Cultura Económica, Madrid, 2009.

Cebollero Martínez, Conrado, Escribir para pensar: la doctrina como motor de la innovación. Instituto Español de Estudios Estratégicos, 2019.

de Londoño, Sancho, Discurso sobre la forma de reducir la Disciplina Militar a mejor y antiguo estado. Ministerio de Defensa, Madrid, 1992.

Frías Sánchez, Carlos Javier, El sistema internacional y las Fuerzas Armadas en el horizonte 2050. Documento de Opinión 106. IEEE, Madrid 2017.

Gat, Azar, War in Human Civilization. Oxford: Oxford University Press, 2008.

González-Pola de la Granja, Pablo, La configuración de la mentalidad militar contemporánea y el movimiento intelectual castrense. El siglo crítico 18001900. Universidad Complutense, Madrid, 2002.

Herbert, Paul H., Deciding What Has to Be Done: General William E. DePuy and the 1976 Edition of FM 100-5, Operations. Leavenworth Papers No 16, Combat Studies Institute, US Army CGSC, Fort Leavenworth, Kansas, 1988.

Kaplan, Lawrence S., Ronald D. Landa y Edward J. Drea. "The McNamara Ascendancy; 1961-1965". History of the Office of the Secretary of Defense, Vol. V. OSD, Washington D.C. 2006.

Matthews, Matt M., We Were Caught Unprepared: The 2006 Hezbollah-Israeli War. The Long War Series Occasional Paper 26. Fort Leavenworth, Kansas: Combat Studies Institute Press, 2008.

Meilinger, Phillip S., The origins of effect-based operations. Joint Force Quarterly, otoño 2004, Nº 35.

Ministerio de Defensa. Publicación Doctrinal Conjunta PDC-01(A) Doctrina para el empleo de las Fuerzas Armadas. Madrid 2018.

Parker, Geoffrey, The Cambridge History of Warfare. Cambridge: Cambridge University Press, 2005.

Rosen, Stephen Peter, Winning the Next War: Innovation and the Modern Military. Cornell University Press, Ithaca, 1994.

Sumida, Jon Tetsuro, Decoding Clausewitz: A New Approach to On War. Lawrence, Kansas: University Press of Kansas, 2008.

Tilly, Charles, Capital, coerción y Estados europeos: 900-1990. Madrid, Alianza Editorial, 1992.

Toffler, Alvin, La tercera ola. Barcelona: Plaza \& Janes, 1998.

Tucídides, Historia de la Guerra del Peloponeso. Planeta De Agostini, Barcelona, 1996. 
Valdés Guía, Pedro, La dirección de la guerra: conducción operacional y gobierno político de las operaciones militares. Tesis Doctoral, Universidad de Navarra, Pamplona, 2019. 